\title{
Assessment of retrospective rabies suspected cases registered at two hospitals, community and tradi- tional healers' knowledge, attitude and practices in south Ethiopian pastoralist.
}

\author{
Balako Gumi ${ }^{* 1,2}$ Sisay Girma ${ }^{2}$, Hussein Mohamed ${ }^{2}$, Oudessa Kerro ${ }^{3}$ and Hassen \\ Chaka $^{4}$ \\ ${ }^{1}$ Addis Ababa University, College of Veterinary Medicine \& Agriculture, Department of Microbiol- \\ ogy \& Veterinary Public Health, P.O. Box 34, Bishoftu, Ethiopia \\ ${ }^{2}$ Bule Hora University, College of Agriculture, P.O. Box 144, Bule Hora, Ethiopia \\ ${ }^{3}$ The University of Tennessee, Department of Animal Science, Knoxville, TN 37996, USA \\ ${ }^{4}$ Food and Agricultural Organization of united nations, Addis Ababa, Ethiopia \\ *Corresponding author: Tel: +251930069300.E-mail address: balako.gumi@yahoo.com.
}

\begin{abstract}
Despite of available protective rabies vaccines for both human and animal, transmission of rabies from animals to people continues in Africa and Asia. Every year, over 59,000 people are estimated to die from the disease globally. Most of industrialized countries in Europe and North America have eliminated rabies from domestic dog populations. However, in the majority of developing countries, rabies remains endemic in domestic dog and poorly controlled. To understand rabies situation in pastoralist and agro-pastoralists area of southern Ethiopian, retrospective data on 431 rabies suspected animal bite cases registered at Bule Hora and Yabello Hospitals were collected and reviewed. Moreover, the knowledge, attitude and practice of 107 selected community members and 55 traditional healers were assessed. Out of 431 cases, $55.7 \%$ and $24.4 \%$ were $\leq 15$ and between 16-25 years age group, respectively. There were more male $55.5 \%$ cases than female $44.5 \%$. Only $32 \%$ of cases registered at Yabello Hospital received post exposure prophylaxis (PEP), whereas the remaining referred to other health facilities. Ninety eight percent (98\%) of animal responsible for the bite was dog and the remaining were cat, fox and donkey. Most of bites were occurred in March-June (36.2\%) and November-February (35.5\%). Out of interviewed participants $87.8 \%$ of them know rabies and $83.2 \%$ were able to mention rabid animals' symptoms. The $78.5 \%$ of participants did mention how rabies transmitted to dog and $88.1 \%$ of them described dog as main source of infection. The $91.6 \%$ of participants told us that rabies is transmit-
\end{abstract}


ted to human by rabid animals' bite and $94.3 \%$ of them believe that rabies is treatable disease and the major means of prevention is traditional treatment. Almost all traditional healers mention that the symptom of rabies in human and animals, and its way of transmission; however $90.9 \%$ of them believe that traditional treatment as effective means of rabies control. Interview result of both community members and traditional healers indicated that most of the rabies cases treated by the traditional healers. Health service providers have to make PEP vaccines available for bite victims and need to raise awareness of the local communities through health education about rabies and animal bite management.

Keyword: Retrospective Study; Rabies; South Ethiopia; pastoralists

\section{Introduction}

Rabies is one of the highly fatal zoonosis, but globally neglected, more specifically in developing countries (Knobel et al., 2005). The disease is caused by a negative-stranded RNA virus of the Rhabdovirdae family (Dietzschold et al., 2005)a negative-stranded RNA virus of the rhabdovirus family. RV pathogenesis, like that of other viruses, is a multigenic trait. Recent findings indicate that in addition to the RV G protein viral elements that regulate gene expression, especially expression of the $\mathrm{L}$ gene, are also likely to play a role in $\mathrm{RV}$ pathogenesis. In vivo, $R V$ infects almost exclusively neurons, and neuroinvasiveness is the major defining characteristic of a classical RV infection. A key factor in the neuroinvasion of RV is transsynaptic neuronal spread. While the ability of $\mathrm{RV}$ to spread from the post-synaptic site to the pre-synaptic site is mediated by the RV G protein, the RV P protein might be an important determinant of retrograde transport of the virus within axons. Although the mechanism(s and a fatal disease that affects domestic and wild animals, and is spread to people through close contact with infectious material, usually saliva, via deep bites or scratches. Once the symptoms of the disease have developed, rabies is nearly always fatal. Dogs are the main host and transmitter of rabies (Vodopija et al., 2016). Despite of available protective rabies vaccines for both human and animal, transmission from animals to people continues. In Africa and Asia, more than 59,000 people die annually from the disease (Léchenne et al., 2016; Zinsstag et al., 2017). Most of industrialized countries in Europe and North America have eliminated rabies from domestic dog populations (Hampson et al., 2015). A concerted effort by South and Central American countries has reduced dog rabies transmission close to elimination (Hampson et al., 2007). 
However, in the majority of developing countries, rabies remains endemic in domestic dog and poorly controlled (Hampson et al., 2015).

Ethiopia has one of the highest incidence levels of human rabies in Africa, with 3-7 deaths per 100,000 people annually (Beyene et al., 2018). Deressa et al 2010 reported 35-58 annual human death due to rabies in Addis Ababa and its surrounding during 2001-2009 (Deressa et al., 2010). The impact of rabies in Ethiopia is aggravated due to limited availability, accessibility, affordability, awareness and knowledge of rabies PEP after exposure to rabid dogs and other animals (Jemberu et al., 2013). In addition to health impact the disease also affect livelihood through losses of valuable livestock and cost of travel to health center for PEP treatment (Yimer et al., 2002). Jibat et al estimated annual national economic losses of 209 million USD due to rabies in cattle (Jibat et al., 2016) and on average 2 million USD treatment costs for PEP in Ethiopia (Beyene et al., 2018).

In Ethiopia, the majority of rabies cases are diagnosed on clinical symptoms only, attributed to the distance to centrally located diagnostic facility at Ethiopian Public Health Institute, and the absence of a reliable laboratory-based surveillance system in the rest of country. Consequently, rabies case reporting rate from urban and rural sectors are low. The majority of exposed patients use traditional healers, in particularly in the rural areas. The limited available data indicates that it is the disease of public health, economic and social concern (Jibat et al., 2016). Given the uncertain rabies situation in the Ethiopian, specifically in West Guji and Borena Zones, it was an important to assess the situation of the disease in the areas as well as knowledge, attitude and practice of the people towards rabies in general. The aim of study was to contribute to better understanding of situation of the disease that would, in turn assist control measures. Therefore, the case records of rabies suspected animal bites were retrospectively assessed in Bule Hora and Yabello Hospitals in southern Ethiopia. Knowledge, attitude and practice of the people and traditional healers about rabies were also assessed.

\section{Materials and Methods}

\section{The study area}

Retrospective study was conducted in 2016, in West Guji and Borena Zones of Oromia regional state in south Ethiopia. The zonal capitals, Bule Hora and 
Yabello, are located at 470 and $560 \mathrm{~km}$ from Addis Ababa, respectively (Fig. 1). The two zones has an area of 45,435 square kilometers, a human population of 1.15 million and a livestock population of 1.13 million cattle, 1.06 million small ruminants, 0.072 million equines and 0.1 million camels (CSA, 2011).

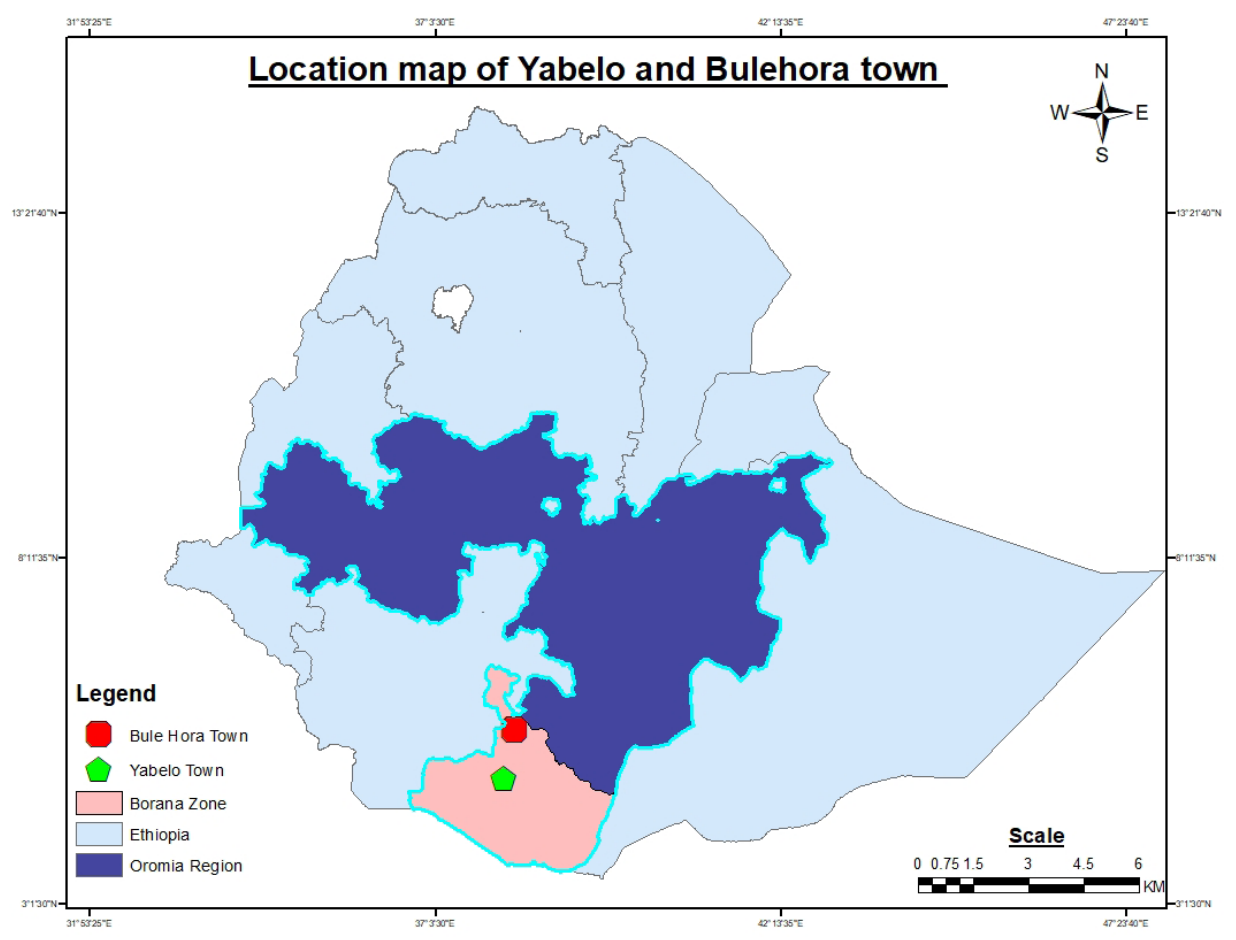

Figure 1: Map of Yabello and Bule Hora town

\section{Sampling methods}

Bule Hora and Yabello districts were selected purposively due to availability of hospitals from West Guji and Borena zones, respectively. There were only two hospitals in the two zones. Cases registered from November 2014-June 2016 at Yabello and March 2015 - September 2016 at Bule Hora Hospitals were reviewed. A predesigned format was used to collect data that basically establish age and sex profiles of patients, patient management at hospitals, if died case report, season of case report, animal responsible for bite. Two hundred sixtyeight and 163 rabies suspected case records were reviewed from Yabello and Bule Hora Hospitals, respectively. 
Twenty-three and 19 Kebeles (a lowest government administrative unit) were randomly selected from list of kebeles in Bule Hora and Yabello district, respectively. In Bule Hora, 3 urban and 20 rural kebeles were included, while all 19 kebeles in Yabello district were from rural areas. Data was collected through a structured questioner survey. Questionnaire was translated into Afaan Oromo (a local language), and interview was made in Afaan Oromo. One hundred seven (107) voluntary community members and 55 traditional healers were interviewed. The questionnaires address the respondents' knowledge about rabies (causes, means of transmission, treatment after animal bite and prevention methods). The questionnaires for traditional healers explore their knowledge about rabies and how they handle rabies cases. All participants gave their oral informed consent before interview.

\section{Data management and analysis}

Data collected were coded and entered into Microsoft Excel spreadsheet, double checked with questionnaire information to avoid errors and then cleaned data import to STATA. Descriptive statistics such as frequency and percentage were used to summarize the data.

\section{Result}

Among 431 rabies suspected animal bite cases $55.7 \%$ were children (age $\leq 15$ years) and $24.4 \%$ young (16-25 years) age group. There was more male $55.5 \%$ cases than female $44.5 \%$. Two hundred sixty-eight cases registered at Yabello Hospital, only $32 \%$ were received PEP, whereas all cases registered at Bule Hora Hospital received PEP. Out of animals responsible for the bites, 98\% were dogs and the remaining were cat, fox and donkey. Over all cases registered at two hospitals, $67.7 \%$ of them were received PEP, while $32.3 \%$ was made wound treatment and referred to other health facilities. The majority of cases were occurring in summer (36.2\%) and winter (35.5\%) seasons (Table 1 ). 
Table 1: Rabies suspected animal bites registered at Bule Hora and Yabello Hospitals

\begin{tabular}{|c|c|c|c|}
\hline Variables & Categories & Frequency $(\%)$ & P-Value \\
\hline \multirow[t]{2}{*}{ Hospitals(N=431) } & Bule Hora & $163(37.8)$ & \\
\hline & Yabello & $268(62.2)$ & \\
\hline \multirow[t]{2}{*}{ Gender } & Male & $239(55.5)$ & 0.262 \\
\hline & Female & $192(44.5)$ & \\
\hline \multirow[t]{4}{*}{ Cases by age categories $(\mathrm{N}=431)$} & $\leq 15$ & $240(55.7)$ & 0.118 \\
\hline & $16-25$ & $105(24.3)$ & \\
\hline & $26-35$ & $37(8.6)$ & \\
\hline & $>35$ & 49 (11.4) & \\
\hline \multirow[t]{4}{*}{ Animals responsible for bite $(\mathrm{N}=405)$} & Dog & $397(98)$ & 0.001 \\
\hline & Cat & $2(0.5)$ & \\
\hline & Fox & $1(0.3)$ & \\
\hline & Donkey & $5(1.2)$ & \\
\hline \multirow[t]{2}{*}{ Care given at hospitals $(\mathrm{N}=368)$} & $\begin{array}{l}\text { PEP (Bule Hora }=163, \\
\text { Yabello=86) }\end{array}$ & $249(67.7)$ & \\
\hline & $\begin{array}{l}\text { Referred (Bule Hora }=0 \text {, } \\
\text { Yabello=119)) }\end{array}$ & $119(32.3)$ & \\
\hline \multirow[t]{4}{*}{ Cases by four seasons $(\mathrm{N}=431)$} & Mar-June (major rain) & $156(36.2)$ & 0.001 \\
\hline & $\begin{array}{l}\text { July-August (minor dry } \\
\text { season) }\end{array}$ & $63(14.6)$ & \\
\hline & $\begin{array}{l}\text { Sept-Oct. (minor rain } \\
\text { season) }\end{array}$ & $59(13.7)$ & \\
\hline & $\begin{array}{l}\text { Nov-Feb (Major dry } \\
\text { season) }\end{array}$ & $153(35.5)$ & \\
\hline $\begin{array}{l}\text { Rabies suspected case death report } \\
(\mathrm{N}=431)\end{array}$ & Death* & $1(0.23)$ & \\
\hline
\end{tabular}

The knowledge and practices of 107 interviewed participants revealed that $87.8 \%$ of them has knowledge of dog rabies while, $12.3 \%$ has no knowledge of dog rabies. Seventy two percent (72\%) of the participant own dogs and uses dog as house or livestock guard. Out of 107 participants, $83.2 \%$ were able to mentioned rabid animals' symptoms, while the remaining $16.8 \%$ unable to describe rabies symptom. The $78.5 \%$ of participants were mentioned how rabies transmitted to dog and $88.1 \%$ of them described a dog as main source of infection. Most of the participants (91.6\%) mentioned that rabies transmitted to human by rabid animals' bites, 5.6\% described as eating raw meat transmit 
rabies, while the remaining $2.8 \%$ didn't know how rabies transmit. Thirtyeight-point three percent (38.3\%) of interviewed participants didn't know the reservoir of rabies, while the remaining participants mentioned either dog or other animals as reservoirs. Among interviewed participants $59.8 \%$ of them; their family members were exposed to rabid animals during the last 10 years. The family members exposed to bites, $43.5 \%$ of them exposed more than two times. About $73.4 \%$ of victims were treated by traditional healers. Most of victims were children $64.7 \%$ and women $23.5 \%$. The $94.3 \%$ of participants believe that rabies is a curable disease. Among $66.4 \%$ of participants who believe that human rabies is preventable; they mentioned that the prevention is made by traditional treatment $60.6 \%$, killing rabid animals $14.1 \%$, dog control $7 \%$ and by avoiding contact with rabid animals $2.8 \%$ (Table 2 ).

The interview result of traditional healers revealed that $80.4 \%$ of them were illiterate (can't read and write) and 54.7\% of them has more than 20 years of traditional healers' services. The 58.5\% (31/53) participants mentioned that dog as the animal affected by rabies, while, $41.5 \%$ of them mentioned that rabies can affect all animal species. Almost all participants mentioned that one or more symptoms of rabies in animals and human (Table 3). Almost all $(98.2 \%)$ of participants mentioned that rabies as a treatable disease and $90.9 \%$ of them believe that the traditional treatment is an effective control method for rabies. Among $87.3 \%$ of the traditional healers who had opportunity to treat rabies suspected exposure cases they clam $93.8 \%$ of them as successful and 6.2 $\%$ as failure (Table 3). 
Table 2: Knowledge, Attitude and Practice of 107 interviewed participants.

\begin{tabular}{|c|c|c|c|}
\hline \multirow[t]{2}{*}{ Variables } & \multirow[t]{2}{*}{ Categories } & \multicolumn{2}{|c|}{ Frequency (\%) } \\
\hline & & Yes & No \\
\hline \multirow[t]{2}{*}{ Participants by District $(\mathrm{N}=107)$} & Bule Hora & $66(61.7)$ & \\
\hline & Yabello & $41(38.3)$ & \\
\hline Own $\operatorname{dog}(\mathrm{s})(\mathrm{N}=107)$ & & $77(72)$ & $30(28)$ \\
\hline Purpose to keep dog (N=77) & House/livestock guard & $77(100)$ & \\
\hline Know dog rabies $(\mathrm{N}=107)$ & & $94(87.8)$ & $13(12.2)$ \\
\hline \multirow[t]{3}{*}{ Rabies symptom (N=89) } & prodromal & $4(4.5)$ & \\
\hline & furious & $38(42.7)$ & \\
\hline & paralytic \& furious & $47(52.8)$ & \\
\hline \multirow[t]{3}{*}{ From where dog acquired rabies $(\mathrm{N}=84)$} & Dog & $74(88.1)$ & \\
\hline & Other animals & $7(8.3)$ & \\
\hline & Environment & $3(3.6)$ & \\
\hline \multirow[t]{3}{*}{ Reservoir of dog rabies $(\mathrm{N}=107)$} & Dog & $45(42.1)$ & \\
\hline & Other animals & $21(19.6)$ & \\
\hline & Don’t know & $41(38.3)$ & \\
\hline \multirow[t]{3}{*}{ How rabies transmits to human $(\mathrm{N}=107)$} & Biting by rabid animal & $98(91.6)$ & \\
\hline & Eating raw meat & $6(5.6)$ & \\
\hline & Don't know & $3(2.8)$ & \\
\hline $\begin{array}{l}\text { Experience of family member bitten by } \\
\text { animals in last } 10 \text { years }(\mathrm{N}=107)\end{array}$ & & $64(59.8)$ & $43(40.2)$ \\
\hline \multirow[t]{2}{*}{ Frequency of bite $(\mathrm{N}=62)$} & At least once & $35(56.5)$ & \\
\hline & $\geq 2$ times & $27(43.5)$ & \\
\hline \multirow[t]{3}{*}{ Where did Victim treated $(\mathrm{N}=64)$} & $\mathrm{PEP}^{*}$ & $16(25)$ & \\
\hline & Traditional medicine & $47(73.4)$ & \\
\hline & local wound treatment & $1(1.6)$ & \\
\hline \multirow[t]{5}{*}{ Most victim dog/animal bite $(\mathrm{N}=102)$} & Men & $8(7.8)$ & \\
\hline & Women & $24(23.5)$ & \\
\hline & men and women & $2(2)$ & \\
\hline & Children & $66(64.7)$ & \\
\hline & children and women & $2(2)$ & \\
\hline Is human rabies treatable $(\mathrm{N}=106)$ & & $100(94.3)$ & $6(5.7)$ \\
\hline \multirow{5}{*}{$\begin{array}{l}\text { How human rabies can be prevented } \\
(\mathrm{N}=71)\end{array}$} & Vaccination & $11(15.5)$ & \\
\hline & Traditional treatment & $43(60.6)$ & \\
\hline & Dog control & $5(7)$ & \\
\hline & $\begin{array}{l}\text { Avoid contact with rabid } \\
\text { animals }\end{array}$ & $2(2.8)$ & \\
\hline & Kill rabid animals & $10(14.1)$ & \\
\hline
\end{tabular}

*PEP $=$ Post exposure prophylaxis 
Table 3: Knowledge, Attitude and Practice of 55 interviewed traditional healers.

\begin{tabular}{|c|c|c|c|}
\hline \multirow[t]{2}{*}{ Variables } & \multirow[t]{2}{*}{ Categories } & \multicolumn{2}{|c|}{ Frequency (\%) } \\
\hline & & Yes & No \\
\hline \multirow[t]{2}{*}{ Participant by district $(\mathrm{N}=55)$} & Bule Hora & $42(76.4)$ & \\
\hline & Yabello & $13(23.6)$ & \\
\hline \multirow[t]{3}{*}{ Education status $(\mathrm{N}=51)$} & Illiterate (can't read \& write) & $41(80.4)$ & \\
\hline & Elementary (grade 1-8) & $8(15.7)$ & \\
\hline & High school (9-12) & $2(3.9)$ & \\
\hline \multirow[t]{3}{*}{ Service year as healer $(\mathrm{N}=53)$} & $<10$ & $10(18.9)$ & \\
\hline & $10-20$ & $14(26.4)$ & \\
\hline & $>20$ & $29(54.7)$ & \\
\hline \multirow{2}{*}{$\begin{array}{l}\text { Animal affected by rabies } \\
(\mathrm{N}=53)\end{array}$} & $\operatorname{dog}$ & $31(58.5)$ & \\
\hline & All animal species & $22(41.5)$ & \\
\hline \multirow{3}{*}{$\begin{array}{l}\text { Rabies symptom in animals } \\
(\mathrm{N}=55)\end{array}$} & Prodromal & $6(10.9)$ & \\
\hline & Furious & $6(10.9)$ & \\
\hline & Paralytic & $43(78.2)$ & \\
\hline \multirow{2}{*}{$\begin{array}{l}\text { Rabies symptom in human } \\
(\mathrm{N}=54)\end{array}$} & Anxiety & $52(96.3)$ & \\
\hline & Confusion & $2(3.7)$ & \\
\hline Is rabies treatable $(\mathrm{N}=55)$ & & $54(98.2)$ & $1(1.8)$ \\
\hline \multirow[t]{2}{*}{ Treatment for rabies $(\mathrm{N}=55)$} & Traditional treatment & $50(90.9)$ & \\
\hline & Modern & $5(9.1)$ & \\
\hline $\begin{array}{l}\text { Experience to treat rabies } \\
\text { cases }(\mathrm{N}=53)\end{array}$ & & $49(92.5)$ & $4(7.5)$ \\
\hline \multirow[t]{2}{*}{ outcome of treatment $(\mathrm{N}=48)$} & Cured & $45(93.8)$ & \\
\hline & death & $3(6.2)$ & \\
\hline
\end{tabular}

\section{Discussion}

In the present retrospective case study, among rabies suspected animal bite In the present retrospective case study, among rabies suspected animal bite cases, $55.7 \%$ were children while $24.4 \%$ young age group. There were more male cases than female, $55.5 \%$ and $44.5 \%$, respectively. Comparable reports were from Oman, $70 \%$ male cases, and $26 \%$ of $10-19$ age group (Abaidani et al., 2015), $62.8 \%$ male cases and $38.5 \%$ of cases were children in Ethiopia (Yibrah 
and Damtie, 2015). Teklu et al from Ethiopia was reported more male cases (63\%) and children (63\%) (Teklu et al., 2017). More male exposure to animal bite may be due to the fact that men tends to approach or handle animals with strange behavior, while children are more friend with pet when they are healthy and easily exposed to bite when rabid.

Among animal species responsible for the bites $98 \%$ was due to dog, while the remaining were cat, fox and donkey. Different report was from Oman where most common bites from cats (Abaidani et al., 2015). This difference may be due to cultural and religion differences to keep dog as pet animal. All cases registered at Bule Hora Hospital received PEP; whereas only $32 \%$ of cases registered at Yabello Hospital received PEP. Beyene et al (2018) reported similar finding from Yabello district that among 87 suspected victims only $28.7 \%$ were received PEP (Beyene et al., 2018). This low proportion of access to PEP was due to PEP vaccine unavailability. Most of the cases were occurred in main rainy and main dry seasons.

There was similar report from Amhara region of Ethiopia (Yibrah and Damtie, 2015). These seasonal differences may be due to the dogs' seasonal activities, such as breeding seasons in rainy season and dogs' migration to urban village for food scavenging in the dry season.

In the present study $87.8 \%$ of interviewed participants have knowledge of dog rabies and $72 \%$ of them use dog as guarding house or their livestock. When livestock guarding dog get rabid it can bite lot of village livestock and herding children before family recognized the disease. Among 107 participants, $83.2 \%$ of them mentioned rabies symptom and $78.5 \%$ of them described how dog contract the disease. The $91.6 \%$ of the participants mentioned that rabies transmitted to human by rabid animal bites. The comparable result was reported from Addis Ababa and northern Ethiopian (Ali et al., 2013; Jemberu et al., 2013) and Tanzania (Sambo et al., 2014). Regarding practice and exposed family members' managements, $73.4 \%$ of them were treated by traditional healers. Jemberu et al reported higher rate of victims treated by traditional healers in north Ethiopia than present result (Jemberu et al., 2013). This difference may be due to level of awareness or trust on traditional healers than modern medicine in the northern Ethiopia.

Among the interviewed 55 traditional healers, 80.4\% of them were illiterate (can't read \& write) and almost all of them mentioned rabies symptom and 
as treatable disease. Most of traditional healers, $90.9 \%$ of them believe that traditional treatment is an effective control method. This high level of belief on traditional treatment may be due to a knowledge on disease causing agent or healers wants to keep their respect in the community and healing/treating as source of income and economic benefit. Almost all traditional healers use the plants for both human and animals healing purposes. Among $87.3 \%$ of the traditional healers who had opportunity to treat rabies suspected exposure cases $93.8 \%$ of them reported as successful while $6.2 \%$ as failure. However, the traditional healers claim such high rate of their treatment success, it must be handled with care in such a fatal disease unless it supported by scientific evidence. Moreover, cases they report may be bite victim than clinical cases.

Among $71.3 \%$ of rabies suspected animal bites, who registered at Yabello Hospital didn't receive PEP vaccine and further referred to other health providing facilities. Those victims were exposed to additional cost of travel and accommodation at treatment centers. Furthermore, it can delay start of PEP time and can increase the risk of onset of clinical rabies. Both interview result of 107 participants and 55 traditional healers indicated that most of rabies suspected animals bite victims rely on traditional healers' treatment and trust them than the government health providers. The local communities trust and dependency on traditional healers than the government may be due to strong cultural linkage with traditional healers and government service unavailability in the area. Therefore, this needs attention of regional and local health service providers to make available vaccines for PEP and create awareness through health education on rabies for local communities. Further study is needed to include more area coverage and retrospective study.

The limitations of present study were; retrospective rabies data on animal was not available, reported human death case in this study was not confirmed by laboratory diagnosis and only based on clinical diagnosis.

\section{Acknowledgement}

We would like to thanks Bule Hora University for financial support to research work and Bule Hora and Yabello Hospitals for the cooperation to review case records. We would like to thanks also interview participants for their cooperation and their time for face to face interview. 


\section{Funding source}

The financial support for this retrospective study was obtained from the Bule Hora University research budget, Bule Hora Ethiopia.

\section{Compliance with ethical standards}

For questionnaire survey participants were briefed about the objectives of the study. All participants gave their oral informed consent before the interview.

\section{Conflict interest}

The authors declare that there is no conflict of interest.

\section{References}

Abaidani, I.A., Abri, S.A., Prakash, K.P., Hussain, M. Hassan, Hussain, M. Hammad and Rawahi, A.H.A., 2015. Epidemiology of rabies in Oman: a retrospective study (1991-2013). Eastern Med. Health J., 21(8), 591-597

Ali, A., Ahmed, E.Y. and Sifer, D., 2013. A Study on Knowledge, Attitude and Practice of rabies among residents in Addis Ababa, Ethiopia. Ethiop. Vet. J., 17, 19-35

Beyene, T.J., Mourits, M.C.M., Kidane, A.H. and Hogeveen, H., 2018. Estimating the burden of rabies in Ethiopia by tracing dog bite victims. PloS One, 13, e0192313

CSA, 2011. Central Statistical Agency Report, (Addis Ababa, Ethiopia)

Deressa, A., Ali, A., Beyene, M., Newaye, B., Yimer, E. and Hussen, K., 2010. The status of rabies in Ethiopia: A retrospective record review Ethiop. J. Health Dev., 24, 127-132

Dietzschold, B., Schnell, M. and Koprowski, H., 2005. Pathogenesis of rabies Current Topics in Microbiology and Immunology, 292, 45-56.

Hampson, K., Coudeville, L., Lembo, T., Sambo, M., Kieffer, A., Attlan, M., Barrat, J., Blanton, J.D., Briggs, D.J., Cleaveland, S., Costa, P., Freuling, C.M., Hiby, E., Knopf, L., Leanes, F., Meslin, F.-X., Metlin, A., Miranda, M.E., Müller, T., Nel, L.H., Recuenco, S., Rupprecht, C.E., Schumacher, C., Taylor, L., Vigilato, M.A.N., Zinsstag, J., Dushoff, J. and Global Alliance for Rabies Control Partners for Rabies Prevention, 2015. Estimating the global burden of endemic canine rabies. PLoS Negl. Trop. Dis., 9, e0003709. 
Hampson, K., Dushoff, J., Bingham, J., Brückner, G., Ali, Y.H. and Dobson, A., 2007. Synchronous cycles of domestic dog rabies in sub-Saharan Africa and the impact of control efforts Proceedings of the National Academy of Sciences of the United States of America, 104, 7717-7722

Jemberu, W.T., Molla, W., Almaw, G. and Alemu, S., 2013. Incidence of rabies in humans and domestic animals and people's awareness in North Gondar Zone, Ethiopia. PLoS Negl. Trop. Dis., 7, e2216

Jibat, T., Mourits, M.C.M. and Hogeveen, H., 2016. Incidence and economic impact of rabies in the cattle population of Ethiopia. Prev. Vet. Med., 130, 67-76

Knobel, D.L., Cleaveland, S., Coleman, P.G., Fèvre, E.M., Meltzer, M.I., Miranda, M.E.G., Shaw, A., Zinsstag, J. and Meslin, F.-X., 2005. Re-evaluating the burden of rabies in Africa and Asia. Bull.World Health Organ., 83, 360-368

Léchenne, M., Oussiguere, A., Naissengar, K., Mindekem, R., Mosimann, L., Rives, G., Hattendorf, J., Moto Daugla, D., Alfaroukh, I., Zinsstag, J. and Technical Committee, 2016. Operational performance and analysis of two rabies vaccination campaigns in N"Djamena, Chad. Vaccine, 34, 571-577

Sambo, M., Lembo, T., Cleaveland, S., Ferguson, H.M., Sikana, L., Simon, C., Urassa, H. and Hampson, K., 2014. Knowledge, attitudes and practices (KAP) about rabies prevention and control: a community survey in Tanzania. PLoS Negl. Trop. Dis., 8, e3310

Teklu, G.G., Hailu, T.G. and Eshetu, G.R., 2017. High Incidence of Human Rabies Exposure in Northwestern Tigray, Ethiopia: A Four-Year Retrospective Study. PLOS Negl. Trop. Dis., 11, e0005271

Vodopija, R., Racz, A. and Pahor, Đ., 2016. The incidence of Jackal bites and injuries in the Zagreb anti rabies clinic during 1995-2014 period. Acta Clin. Croat., 55, 151-155

Yibrah, M. and Damtie, D., 2015. Incidence of human rabies exposure and associated factors at the Gondar Health Center, Ethiopia: a three-year retrospective study. Infect. Dis. Poverty, 4(1), 3

Yimer, E., Newayeselassie, B., Teferra, G., Mekonnen, Y., Bogale, Y., Zewde, B., Beyene, M. and Bekele, A., 2002. Situation of Rabies in Ethiopia: A retrospective study 1990-2000. Ethiop. J. Health Dev., 16(1), 105-112

Zinsstag, J., Lechenne, M., Laager, M., Mindekem, R., Naïssengar, S., Oussiguéré, A., Bidjeh, K., Rives, G., Tessier, J., Madjaninan, S., Ouagal, M., Moto, D.D., Alfaroukh, I.O., Muthiani, Y., Traoré, A., Hattendorf, J., Lepelletier, A., Kergoat, L., Bourhy, H., Dacheux, L., Stadler, T. and Chitnis, N., 2017. Vaccination of dogs in an African city interrupts rabies transmission and reduces human exposure. Sci. Transl. Med., 9

Ethiop. Vet. J., 2019, 23 (2), 77-89 